that gets the blame. Applying this dictum to the bladder tumours, the committees found that since saccharin has been used for longer than cyclamates without apparently harmful effects, it must have been the cyclamate which caused the tumours. They therefore recommended to the minister that it would be prudent to stop further addition of cyclamates to food until the research programme half completed by the British Industrial Biological Research Association (BIBRA) has been brought to a conclusion. Scarcely twenty-four hours later, on October 24, a happy Mr Cledwyn Hughes was able to announce that the vicious sweetener was to be phased out.

The postscript to this seven day wonder has been afforded by a spokesman at the Ministry of Agriculture. Asked why such terrible speed was necessary, he admitted that "Public opinion wanted an answer straight away. We'd have been caught very much with our head in the sand if we didn't do anything about the cyclamates. We had either to ban them or prove them harmless". Ostrich-like or not, even the fleet footed Ministry of Agriculture could not prove cyclamates harmless at seven days' notice and, discretion being the better part of valour, it only remained for housewives to be soothed with advice as to what foods and beverages were likely to contain the deadly substance before a grateful public could sink back, probably to soothe itself with a well earned cigarette, confident in the knowledge that its political and scientific guardians would leave no stone unturned to protect the nation's health, save any such as might be inconveniently heavy to uproot.

\section{Herod in Cumberley}

If the Ministry of Agriculture finds itself finally committed to a programme for the extermination of all wildlife in the part of England around Camberley, where a dog died of rabies ten days ago, its most serious problem will be to know just what has got away. There is historical evidence to show how difficult is a programme of complete eradication. Wildlife on an open common is particularly hard to control and exterminate. It may be possible to get rid of the foxes but nobody will be sure, perhaps for a year or so, that other forms of wildlife are not affected.

The problem of rabies in developed countries is peculiar. For one thing, the disease itself has a mediaeval quality. The horrific tales of how people used to die from it in the Middle Ages are too vivid to be forgotten. But rabies is also almost mediaeval in the way in which it persists in wildlife and in the way in which it can so easily be transferred from an animal population to human beings. In Britain, rabies was common in the nineteenth century but for practical purposes was eradicated by the beginning of this century. Since then there has been an apparently successful programme of quarantine-domestic animals must spend six months in quarantine before being allowed to mix with their fellows already well established. The dog that died in Camberley seems to have been infected with rabies at a quarantine kennel at which another animal had died of the disease.

Several questions must be asked about the management of the disease. To begin with, there seems no prospect that it would be possible to substitute immunization for quarantine. In the past few months, there has been a tendency to suggest that preferential treatment might be given to imported animals which had been vaccinated or that the quarantine regulations must be relaxed now that the rabies virus has been identified and purified and human vaccines made more effective as a result. Unfortunately, however, as two recent articles in Nature demonstrate (224, 244 and 246; 1969), the use of a human vaccine, like the immuniza- tion of domestic animals, is an unccrtain safeguard. It seems now to be well established that a dog that died in quarantine in 1968 had been vaccinated on several occasions. The use of the human vaccine is hazardous. In brief, the World Health Organization is right to insist that the countries which are now free from rabies should persist with their quarantine regulations. If anything, there is a case for asking that the Jength of the period of quarantine should be increased. If the regulations are given their full meaning, there is also a case for thinking they should apply to imported monkeys as well as dogs, which in turn implies that animals for medical research would have to be obtained by breeding artificially within a quarantine fence. This would add substantially to the cost. There is also a strong case for asking that quarantine kennels such as that in which the Camberley dog picked up its infection should be more strictly managed.

Dogs are the chief hazard to be sure, and for this reason there is even a case for asking whether it would be wise to ban the import of dogs. After all, it is not as if there were a shortage of these animals, and a ban on imports might do no damage to the commercial interests of the British dog breeding industry.

\section{NOBEL PRIZES \\ Honouring Founding Fathers}

Tre sociology of the Nobel Prize is a fascinating subject and a source of endless gossip. What significance, for example, can be attached to the delay between the time when an eventual Nobel laureate is at the peak of his experimental career and when he reaps his reward in Stockholm? Lately the prize committee has to its credit given the prize to comparatively young molecular biologists who were clearly destined to be honoured eventually. But this year, at least as far as the molecular biologists are concerned, the committee seems to have gone back over its lists and corrected an oversight. Max Delbrück, Salvador Luria and Al Hershey who have won this year's Nobel Prize for Medicine are 